\title{
The Food Aid Convention: its history and scope
}

\author{
J. H. Parotte
}

\section{Introduction}

To understand why the Food Aid Convention (FAC) arose and how it works, it is necessary to go back to its origins. For that reason this article will examine first how the FAC was conceived and born. There will follow a brief outline of the contents of the Food Aid Conventions of 1967,1971 and 1980, and a description of the present functions of the Food Aid Committee. Lastly, a few selected facts and figures will be given to highlight the importance of the convention as a vehicle for providing food aid.

\section{Origins}

The first Food Aid Convention came into effect on 1st August 1968. It was one of the two legal instruments - the other being the Wheat Trade Convention which constituted the International Grains Arrangements, 1967. Its conception dates from April 1963, when a new round of tariff negotiations, the 'Kennedy Round', started under the auspices of the General Agreement on Tariffs and Trade (GATT). Although, as in previous negotiations to reduce trade barriers, industrial goods were to be the primary focus, it was decided that agriculture, and more particularly wheat and coarse grains, should also form part of the Kennedy Round.

The GATT cereal negotiations were concluded in May 1967 with the adoption of a Memorandum of Agreement between a number of countries, including the European Economic Community and its six original member states. The Memorandum required the signatories subsequently to negotiate an arrangement containing well-defined basic elements. These related to the trade in wheat, including prices, and a programme of food aid in grains. The latter was the reason why the agreement, which finally emerged

${ }^{1}$ Executive Secretary, International Wheat Council. The designations employed and the presentation of the material in this article do not imply the expression of any opinion on the part of the Secretariat of the International Wheat Council concerning the legal status of any country or territory, or its authorities, or concerning the delimitation of its frontiers. Additional information concerning the Food Aid Convention may be obtained from the Executive Secretary, International Wheat Council, 28 Haymarket, London. from a conference held in Rome in the summer of 1967, was called the 'International Grains Arrangement' (IGA). Despite its name, the IGA did not attempt to regulate trade in all grains: although this was initially the intention, proposals on the coarse grains trade were finally abandoned in the last stages of the GATT negotiations.

It is worth recalling the names of the founder members of the IGA. They were Argentina, Australia, Canada, Denmark, Finland, Japan, Norway, Sweden, Switzerland, the United Kingdom, the United States of America, and the European Economic Community and its six original member states - almost exclusively industrialised countries. The only exception was Argentina, generally regarded as a developing country, although by no means one of the poorest. It is also important to note that the participants included the major wheat exporting countries and some of the main commercial importers, principally the EEC, Japan and the United Kingdom.

To find out why a Food Aid Convention was eventually conceived, it is necessary to look back at the world wheat situation in the late 1950s and early 1960 s. During those years, the stability of the wheat market was assured by the policies of Canada and the United States. Both of them were willing to bear the heavy cost of holding huge stocks off the market. The world wheat situation started to change from one of chronic surpluses to one of tighter supplies when the Soviet crops failed in 1963 and 1965. In a remarkable turn-around of policy, the Soviet Union then entered the international market and made substantial purchases to offset its domestic shortfalls. Two successive monsoon failures in the Indian subcontinent, in 1965 and 1966, further reduced stocks, particularly in the United States. Inevitably, prices rose - rather steeply by the standards of the time

For many years, nearly all food aid had been provided by the United States, and to some extent by Canada, as part of their surplus disposal programmes. It will be recalled that Public Law 480 - better known as PL 480 - came into effect in 1954. It provided, inter 
alia, for the sale of surplus agricultural products for foreign currency, and donations of surplus foods through non-profit relief agencies and intergovernmental organisations. Trade in wheat and flour on concessional terms sometimes reached large proportions - up to $15 \mathrm{mn}$ tons, or one third of world trade, in the early 1960 s. But once availabilities were sharply reduced, continued massive food aid shipments were bound to affect the internal market stability of the two countries. At the same time, the need for food aid, particularly in Asia, was more evident than ever. Not unnaturally, these two main donors began to insist that other countries - which meant, in those days, the other major industrialised exporters and importers, particularly Western Europe and Japan who gave little or no food aid - should shoulder some of the burden. These political and economic pressures led to the negotiation of the Food Aid Convention.

Another belief behind the Food Aid Convention was that, when grain surpluses inevitably reappeared, it would help support the higher prices enshrined in the Wheat Trade Convention, 1967. This in fact proved a fallacious argument for, in the case of Canada and the United States, FAC commitments would not necessarily be additional to what they previously supplied.

Nevertheless, the birth of the Food Aid Convention was a milestone in international cooperation. For the first time a number of governınents were legally bound by international treaty to provide, year in year out, minimum specific quantities of food aid in cereals, especially in tight supply and high price situations. For the first time, too, grain importing countries agreed to play a part with the major grain exporting countries in providing food aid in cereals to the needy populations of the world.

\section{Relationship between the Food Aid and the Wheat Trade Conventions}

As already mentioned, the International Grains Arrangement, 1967 consisted of two Conventions: the Wheat Trade Convention and the Food Aid Convention. The precise nature of the relationship between the two does not seem to be generally understood. They are closely linked as a result of their original negotiation as a package. Bargains struck in 1967 between the participants in the Kennedy Round involved trade-offs, which were not easily to be unravelled. For example, the Food Aid Convention, 1967 could not enter into force unless all the signat ories of the GATT Memorandum of Agreement became party to it as well as to the Wheat Trade
Convention. The formal link between the two Conventions has been maintained ever since.

\section{The Food Aid Convention, 1967}

The objective of the 1967 Convention was to "carry out a food aid programme with the help of contributions for the benefit of developing countries'. The donors agreed to contribute some $4.5 \mathrm{mn}$ tons of grain annually, in the form of wheat or coarse grains, suitable for human consumption (see Table 1).

Importing members, such as the United Kingdom and Japan, which were then unable to meet their obligations from their domestic markets, would have to purchase grain from other members of the Convention, priority being given to developing members. This was intended to benefit Argentina which was, and remains, the only developing member of the Food Aid Convention. Because of the wide fluctuations in its wheat production, Argentina was not able to take full advantage of this possibility to increase its exports.

While aid on non-commercial credit terms could be counted as a part of members' contributions under the Convention, it was understood that most should take the form of gifts or grants. The Convention established a Food Aid Committee, consisting of all the donors, which will be discussed below.

The contributions of the various donors were negotiated in the GATT Kennedy Round on the basis of complex calculations, taking into account their grain production and consumption, and respective $p e r$ capita GDPs. The United States, not unexpectedly, had the largest share: $1.9 \mathrm{mn}$ tons or 42 per cent of the total of $4.5 \mathrm{mn}$ tons. Next came the European Economic Community and its six original member states with $1 \mathrm{mn}$ tons ( 23 per cent), followed by Canada, with $0.5 \mathrm{mn}$ tons ( 11 per cent).

The Convention emphasised the importance of the multilateral channelling of aid, special reference being made to the World Food Programme (WFP). While most FAC aid was, and remains, bilateral, increasing quantities have been channelled through the World Food Programme, which regards them as a most valuable supplement to its regular resources.

\section{The Food Aid Convention, 1971}

On its expiry in 1971, the IGA was replaced by the International Wheat Agreement, 1971, again consisting of two linked Conventions. The terms and provisions of the 1971 Food Aid Convention were similar to those of the 1967 instrument. Initially, its 


\section{Table 1}

Membership and minimum annual contributions under the Food Aid Conventions, 1967, 1971 and 1980 (000 tonnes)

\begin{tabular}{|c|c|c|c|}
\hline \multirow[b]{2}{*}{ member } & \multicolumn{3}{|c|}{ convention } \\
\hline & 1967 & $1971^{1}$ & 1980 \\
\hline Argentina & 23 & 23 & 35 \\
\hline Australia & 225 & 225 & 400 \\
\hline Austria & - & - & 20 \\
\hline Canada & 495 & 495 & 600 \\
\hline Denmark & 27 & 2 & 2 \\
\hline $\begin{array}{l}\text { European Economic } \\
\text { Community and } \\
\text { its member states }\end{array}$ & 1,035 & $1,035^{3}$ & 1,650 \\
\hline Finland & 14 & 14 & 20 \\
\hline Japan & 225 & 225 & 300 \\
\hline Norway & 14 & - & 30 \\
\hline Spain & - & - & 20 \\
\hline Sweden & 54 & 35 & 40 \\
\hline Switzerland & 32 & 32 & 27 \\
\hline United Kingdom & 225 & 2 & 2 \\
\hline $\begin{array}{c}\text { United States of } \\
\text { America }\end{array}$ & 1,890 & 1,890 & 4,470 \\
\hline Total & $4,259^{4}$ & $3,974^{5}$ & $7,612^{6}$ \\
\hline
\end{tabular}

Notes:

- not a member of the Convention;

1 some countries increased their contributions in 1979/80 to the higher levels they had pledged at the United Nations negotiating Conference in 1978-79;

2 Denmark and the United Kingdom were not initially members of the Food Aid Convention, 1971 but joined in 1973 on their accession to the European Economic Community;

3 increased as follows following the accession of Denmark, Ireland and the United Kingdom: $1972 / 73,1,161,000$ tons; $1973 / 74$ to $1979 / 80,1,287,000$ tons.

${ }^{4}$ the parties to the Convention agreed to contribute a combined total of $4.5 \mathrm{mn}$ tons;

5 increased to $4,200,000$ tons in $1972 / 73$ and $4,326,000$ tons in $1973 / 74$ and subsequent years (see footnote ${ }^{3}$ );

${ }^{6}$ the objective of the Convention is 'to secure, through a joint effort by the international community, the achievement in physical terms of the World Food Conference target of at least $10 \mathrm{mn}$ tons of food aid annually to developing countries in the form of wheat and other grains suitable for human consumption'.

membership was slightly smaller. The minimum contributions fell to just below $4 \mathrm{mn}$ tons, as Denmark, Norway and the United Kingdom did not renew their participation. Those three grain importing countries considered that they could help developing countries in better ways, through technical assistance for example, than by providing food aid. Denmark and the United Kingdom rejoined in 1973 on their accession to the European Economic Community, and Ireland became a new member at the same time.

During the life of this Convention the world passed through what has come to be known as the "world food crisis', when stocks dropped sharply and prices soared to unprecedented heights. Supplies of cereals for food aid came under considerable pressure. However, the Food Aid Convention proved its indisputable value by assuring the basic minimum annual flow of around $4 \mathrm{mn}$ tons. At the beginning of the 1970s, annual food aid in grains exceeded $12.5 \mathrm{mn}$ tons, of which about $4.5 \mathrm{mn}$ tons were under the Convention (all of it in the form of gifts), and $8 \mathrm{mn}$ tons outside it. Most of the aid outside the Convention was provided by the United States, some of it in the form of sales for local currency or on credit at low interest rates. With the steep rise in market prices after mid-1972, the amount of food aid dropped considerably, most donors' aid programmes being expressed in financial, rather than quantitative, terms. The low point was in $1973 / 74$ when shipments fell to only $6 \mathrm{mn}$ tons, of which barely $2 \mathrm{mn}$ tons was provided outside the Food Aid Convention.

In retrospect, the 1970 s can be seen as a period of consolidation for the Food Aid Convention. When the first Convention came into effect in 1968, most of the donors had little or no experience of food aid, and it took some of them three to four years to solve the initial teething problems. New thinking on the need for food aid and concern about its role in the development process were also becoming increasingly evident in international discussions, particularly following the World Food Conference in 1974. The new ideas on market stability and world food security were extensively aired at the United Nations negotiating Conference (1978-79) on the replacement of the 1971 Agreement. They were reflected to some extent in the work done on a new Food Aid Convention.

\section{The Food Aid Convention, 1980}

The UN Conference had to be adjourned in February 1979 because participants failed to agree on the basic elements to meet the twin objectives of market stability and food security in a new Wheat Trade Convention. The only concrete achievement of the Conference was its progress in negotiating the Food Aid Convention. The existing members had declared their willingness to increase substantially their commitments. After a series of consultations following the adjournment of the UN Conference, they decided to sever the link between the completion of the Food Aid Convention and the stalled negotiations on the Wheat Trade Convention. 
In March 1980, the Food Aid Committee itself finalised the negotiation of the Food Aid Convention, which came into effect on 1st July 1980. This was arguably the second important milestone in the efforts of the international community to raise the level of food aid in the form of grains to developing countries. Its objective, which is wider than under previous Conventions, is to secure, through a joint effort by the international community, the achievement in physical terms of the World Food Conference target of at least $10 \mathrm{mn}$ tons of food aid annually to developing countries in the form of wheat and other grains suitable for human consumption. As before, the obligations remain basically quantitative, ensuring that the volume of aid is not reduced in times of falling grain supplies and rising prices.

The volume of aid is itself much higher than before. The current 22 donors (who now also include Austria, Norway and Spain) have agreed to contribute a minimum of some $7.6 \mathrm{mn}$ tons annually, abour 80 per cent more than under the previous Conventions. Most food aid in grains now falls within the Convention's ambit. Efforts are continuing to encourage new donors to join the existing ones in order to reach the target of $10 \mathrm{mn}$ tons. They have been directed mainly to oil-producing countries, in particular OPEC members, but have met with little success so far.

It has been suggested in some forums that the $10 \mathrm{mn}$ ton target is too low, and that it should be increased as soon as possible to, perhaps, $15 \mathrm{mn}$ tons or more. ${ }^{2}$ Without entering into the argument as to the future requirements for food aid, it must be said that the existing traditional donor members of the FAC have made it clear that they consider food aid to be the responsibility of all members of the international community. They are, therefore, unlikely to raise their own commitments above present levels in the absence of new donors. Current and potential donors alike are experiencing financial constraints of some kind or another, and it seems doubtful whether commitments under the Food Aid Convention could be formally increased in the near future. Even under more normal economic conditions, it took 10 years to increase the original obligations by 80 per cent to $7.6 \mathrm{mn}$ tons, but this does not preclude higher shipments occasionally, depending on the price level.

Under the Food Aid Conventions, 1967 and 1971, most aid was in the form of grains, predominantly wheat and wheat flour, and coarse grains for human consumption. Aid in the form of rice was only permitted in exceptional circumstances. Under the 1980 Convention rice is now formally allowed.

${ }^{2}$ See Barbara Huddleston's article in this Bulletin.
Some donors wanted to extend the coverage to other commodities, such as dairy products. This was vigorously resisted by others, who argued that the raison d'être of the Food Aid Convention was still to provide aid in the form of cereals. Although the 1980 Convention was negotiated separately from a new Wheat Trade Convention, they continue to be linked: the existence of the Food Aid Convention is still contingent on that of the Wheat Trade Convention.

\section{Tighter Commitments under the 1980 Convention}

Members are, under the new Convention, to make their contributions as far as possible on a forward planning basis. This would enable recipient countries (and, as appropriate, multilateral organisations) to take account of the likely flow of food aid each year. Most members do now engage in forward planning but, as each makes arrangements appropriate to its own financial and other institutional procedures, there is little uniformity. Aid channelled through the WFP is normally committed well in advance of shipment, and much bilateral aid is planned on an annual basis. Emergency aid is, of necessity, provided at short notice.

It is the general aim that the major part of grain purchases resulting from cash contributions should be made from developing members of the Food Aid Convention. So far under the 1980 Convention only a relatively small proportion of aid has taken the form of cash contributions. In 1980/81, for example, only three members (Finland, Japan and Norway) gave cash contributions, totalling US $\$ 46 \mathrm{mn}$. This is equivalent, using the formula laid down in the Convention (see below) to 277,000 tons of grain, or four per cent of total shipments under the Convention. Most of the cash was used to buy rice, some of it from non-member developing countries. No grain was purchased from Argentina, the only developing country member of the Convention, because it had no grain to spare over and above its existing export commitments.

Cash contributions under the 1980 Convention are to be evaluated against the donor's obligations at prevailing market prices. The Convention differs in this respect from its predecessors, under which cash contributions were evaluated at a pre-determined, negotiated price. Under the 1971 Convention the rate used to evaluate cash contributions was US $\$ 64$ per ton. The Rules of Procedure now lay down how the 'prevailing market price' is to be calculated. For contributions in the crop year 1981/82 it was US $\$ 183$ per ton. It is slightly lower for $1982 / 83$ : US $\$ 182$. 
If low income developing countries as a whole suffer a substantial production shortfall in food grains, the Food Aid Committee may recommend that members should increase the amount of aid available to cover emergency needs. The occasion has not yet arisen to put this new provision into effect, but the Food Aid Commit tee has recently been devoting much attention to the way in which it might, when necessary, be applied.

Transactions under the 1980 Convention are to be carried out in a way consistent with the concerns expressed in the FAO Principles of Surplus Disposal and Guiding Lines. Members are also requested to act in accordance with the Guidelines and Criteria for Food Aid, as approved by the Committee on Food Aid Policies and Programmes (CFA) of the World Food Programme.

\section{Multilateral Channels Recommended}

As in the 1971 Convention, members are requested to give full consideration to the advantages of directing a greater proportion of food aid through multilateral channels, particularly the World Food Programme. The WFP played an important role under the 1967 and 1971 Conventions, when, in all, it handled over $2 \mathrm{mn}$ tons of members' contributions, including a high proportion of those which were made in the form of cash (see below).

The WFP uses this aid, which is accompanied by additional cash grants to cover transport and administrative expenses, to assist its projects in various developing countries. Some of the FAC contributions are additional to the regular resources of the WFP, and help to provide the Programme with greater operational flexibility and an enhanced capacity to assist developing countries.

\section{The Food Aid Committee ${ }^{3}$}

The Food Aid Committee, already referred to, is a Committee of donors. In 1967, it had originally been envisaged to include recipients as well, but after lengthy discussions, it was finally decided to limit membership to donors. The Committee, which comprises all members of the Convention, meets regularly twice a year, usually at the end of June and the end of November, in conjunction with the sessions of the International Wheat Council. The Secretariat of the Council also services the Committee.

The primary task of the Committee is to monitor the fulfilment of members' obligations under the

${ }^{3}$ The Food Aid Committee should not be confused with the Committee on Food Aid Policies and Programmes (CFA), composed of both donors and recipients, which supervises the work of the WFP.
Convention. For this purpose, a detailed reporting and recording system has been developed, which has strengthened the Committee's role as a source of comprehensive information on food aid shipments. The other main function of the Committee is to examine in depth the food situation in developing countries and means by which to alleviate food shortages. In this connection it exchanges views with other intergovernmental organisations concerned with food aid.

The Food Convention, 1980 originally had a life of one year, to 30th June 1981, to keep in step with the Wheat Trade Convention, 1971, whose 1979 Protocol of extension was also expiring on that date. In 1981 it was extended for two more years, to 30th June 1983, and at its forty-fourth session on 1st December 1982, the Food Aid Committee agreed to extend it for another three years to 30th June 1986.

\section{Quantities, Commodities and Recipients}

Altogether, under the three Food Aid Conventions of 1967, 1971 and 1980, some $60 \mathrm{mn}$ tons of cereals have been shipped to over 80 developing countries in all parts of the world. About two thirds of the aid normally takes the form of wheat and wheat flour. The balance consists of coarse grains fit for human consumption, particularly maize, and certain grain products, such as wheat soya blend or corn soya milk supplied by the United States. Rice has been shipped in increasing quantities, and most of Japan's aid is now in this form. The latest Convention permits the supply of so-called products of secondary processing, including, for example, macaroni and spaghetti.

Under the 1967 and 1971 Conventions, nearly all aid was in the form of outright gifts. Since the increase in minimum contributions under the 1980 Convention, however, the United States has counted considerable quantities of its concessional sales under Title I of PL 480 towards the fulfilment of its obligations. Most of the aid under the Convention is supplied bilaterally, though an increasing share is channelled through the World Food Programme. In 1980/81, a large proportion of this ( $1.2 \mathrm{mn}$ tons) formed part of the pledges already made by members towards the regular programmes of the WFP and the IEFR; but about 300,000 tons were additional to those pledges and represented a net increase in the WFP's resources. Some donors, for example Finland, Norway and Sweden, channel all of their FAC contributions through the WFP. Many members also make substantial contributions towards the costs of shipping the aid. 
It is difficult to generalise about the distribution of the aid since it varies considerably from year to year. The emphasis on Africa is tending to increase as a result of its precarious food situation. Of the $5.4 \mathrm{mn}$ tons of grain shipped against 1980/81 obligations, ${ }^{4} 2.9 \mathrm{mn}$ tons was supplied to African countries, nearly half of

${ }^{4}$ In terms of wheat equivalent the tonnage shipped was $6.7 \mathrm{mn}$. The shortfall compared with members' combined minimum commitments of $7.6 \mathrm{mn}$ tons has been added to their obligations for 1981/82. it to Egypt. In other parts of the world, the most important destination is Bangladesh, which received $0.5 \mathrm{mn}$ tons in 1980/81. Pakistan, Sri Lanka, Indonesia, Peru and the Philippines also usually receive considerable quantities. Recipients of aid under the Convention are not necessarily among the least developed countries. Destinations recorded in 1980/81 include Brazil, Chile, Cyprus, Israel, Lebanon and Turkey.

For references see page 61 .

\section{The Brandt Commission: a Positive Posilion on Food Aid}

Foodaid Wil conilnue to be essential It has boen oriticlsed in the past, whether tor its political exploitation or tod the disruption of agricultural hoentives in the rectolent countries. But the econemía cruleisms are now less often heard lood ald need not bo a disincentive to. agricuthral producter provided that effective demand for food is raised to clear the market at a proe which revards domestie producers. Many countries will take one or moro decates belore they can selsty thel internal food requirements, and enough food nust ber made avallable to them while they are bulding up their domestic capacity.

Requirements for food ald have usually been calculated according to expected deflcits. But They could be looked at diterenty, if they were also related to programmes tor increasing investment in agriculture such as we have envisaged here. The World Food Conference in 1975 set a target of 10 million tons a year, which has not yet been reached. Indeed. more may be needed if all targets ar e to be met in the near future, ard es pecially if food ald is extended to support investment in agriculture and labour intens) ve public works programmes. Food ard other than cereals is also needed, additional use of some EEC dain surpluses, for example. could be made for this purpose. Food alds havid of course be seen as a complement to other kinds of aid, and given without poltiod strings, and food issues must always be considered in the context of halional agriculur progranmes. 